\title{
On Goal-Driven Principles and Contract Discourse*
}

\author{
Yang Hong \\ Hainan University, Haikou, China; \\ Central China Normal University, Wuhan, China
}

\begin{abstract}
Human beings' speech act has a goal driven. As a written discourse, contract has a very clear goal, which is the essence of it. The overall goal of "Contract Law" is to protect the legitimate rights and interests of the contracting parties, maintain social and economic order, and promote the socialist modernization construction. The key incentive for drafting a contract is the underlying goal, thus each term of the contract and every legal rule are derived from the goal. Liao Meizhen first proposed the theory of pragmatic goal-driven principles (GDP) in pragmatics. Under its guidance, contract discourse will be analyzed from four levels, namely, the national contract legal system, specific contracts of economic agents, contract disputes, and court hearing on contract dispute cases to clarify the rights and obligations of the parties, so as to achieve the economic goal of the contracts.
\end{abstract}

Keywords: speech act, goal-driven principles (GDP), contract discourse analysis

\section{Introduction}

The legal proverb says that the goal of the parties is the soul of the contract. Contract is a contract among equal subjects to establish, change, and terminate the relationship between civil rights and obligations. The contract, as the name implies, is the same. Contract means two parts, namely, "Joint" and "Same". Joint: more than two are united; one is single alone; and Same: The meaning is the same, different is different. The contract has three elements: subject, object, and content. The main body refers to Party A, Party B, supplier, processing party, contractor, etc. The object refers to the object to which the rights and obligations are directed, also known as the subject matter. The content refers to the rights and obligations specified in the contract (Gao, 2004). If the goal orientation of the subject of the contract is inconsistent, the category, subject matter, and content clause of the contract are different. In criticism of judgment, Kant (1946) has two aspects about the concept of goal: One is that "the concept of an object is called goal as far as the basis on which it contains the reality of the object at the same time is concerned". The second is "if we want to explain what an end is based on a transcendental rule, then goal is the object of a concept, as long as the concept is regarded as the reason for that object, that is, the real basis for its possibility” (p. 66).

In the history of philosophy, goal has long been an important principle and played an important role, occupying an important position, but no one has clearly expressed it in the form of the proposition of the principle of goal. Socrates, Plato, Aristotle, Kant, Heger, and other famous philosophers have all discussed the

*Acknowledgement: The paper was part of the One Research Result of Australian Culture and Language Project funded by China Scholarship Council (Project No. Ljf20175087) and One Research Result of Studies on Speech Act Theory and Contract Discourse Project funded by College of Foreign Language, Central China Normal University (Project No. YH2013011008).

Yang Hong, Ph.D., assistant professor, College of Tourism, Hainan University; visiting scholar in Britain, Canada, America, and Australia, won the Canadian Studies Special Award, College of Foreign Language, Central China Normal University. 
goal of their own. However, so far, few people have applied the principle of goal to linguistic and pragmatic analysis. Gu Yueguo, Paris, Karst Franch, Qian Guanlian, and others have put forward rhetorical goal, hyper-linguistic goal, social goal, communicative goal, effective goal, invalid goal, transparent goal, non-transparent goal, communication goal, neutral goal, hidden goal, goal intention principle, and so on. But none of them took the analysis of goal to the level of theory and principle (Gao, 2004). Liao Meizhen (2005a) raised the goal into a clear pragmatic principle, and put forward the pragmatic task under the goal principle, and a set of procedures and methods that can be used for operation, and stressed that "any verbal behavior is essentially a kind of human behavior, and any verbal act is an integral part of the course of the goal sexual behavior" (p. 5). In the works on discourse, the use of discourse, that is, discourse, refers to a communicative event and communicative interaction, emphasizing that discourse refers to both spoken and written language (Van-Dijk, 1980). Contract is a kind of written language, a kind of speech act, and a very goalful written discourse. The soul of the principle of goal theory lies in its implementation, focusing on the use and study of contract discourse, understanding the legislative intention, and analyzing the macro-general goal and micro-cosmic goal of the contract.

\section{Review of Pragmatic Goal-Driven Principles (GDP)}

The theory of pragmatic goal-principles was put forward by Liao Meizhen, a professor of Chinese legal linguistics, in a series of speeches and academic papers at the beginning of the 21st century. In a short period of 10 years, the research has attracted extensive attention in the field of linguistics and law at home and abroad, attracted the research interest of many experts, scholars, and doctoral students, and the scientific research results related to the goal principle and doctoral and master's theses have been emerging.

Since 2002, Liao Meizhen has published or published some scientific research results on the principle of goal, such as his representative results, the study of court question and answer and its interaction, the study of the cooperation between the principle of goal and the interactive discourse of the court, the analysis of the principle of goal and goal (I), the analysis of the principle and goal of goal (second), the analysis of the principle of goal and coherence of discourse, and the study of the principle of goal and communicative model. Research on the principle of goal and communicative model (continued), the dynamic study of the principle of goal and context, the pragmatic analysis model of legal argumentation from the perspective of the principle of goal, and the study of the interaction between the principle of goal and speech act. In Question and Answer: A Study of Court Discourse Interaction, Liao Meizhen put forward for the first time the interaction between question and answer and goal, the goal of human behavior, the study of goal and discourse, the goal relationship of court discourse participants, the difference of goal and question and answer, etc., and expounds and explains the new pragmatic principles of speech act and speech activity, that is, the view of goal principle.

The number of downloads of Liao Meizhen's principle is on the rise, with the lowest number of downloads approaching 500 times, up to 2,035 times. Among them, the top three of the number of downloads are the objective principle and the goal analysis (upper) (lower). In The Goal Principle and the Discourse Coherence Analysis, Liao Meizhen put forward the theory of the principle of the principle of the goal and the reasons for its application in the discourse: The first is to use the goal principle as the guide, and the goal is the core analysis language; the second is to use the goal system theory to explain the coherence of the text. The goal of this paper is to provide a new way to study and explain the coherence of the utterance as the criterion for judging the consistency and the degree of consistency; and the third is the cause of speech act generation 
and the motive force of its development. This is both a philosophical proposition and a pragmatic principle. The number of downloads of Liao Meizhen's principle is on the rise, with the lowest number of downloads approaching 500 times, up to 2,035 times. Among them, the top three of the number of downloads are the objective principle and the goal analysis (upper)/(lower).

The principle of the goal of pragmatics is the foundation of the analysis of the goal of speech act. The goal of the pragmatic study and the speech act analysis is to describe the speech analysis, analyze the speech act, and explain the speech act. The specific contents include goal expression, goal pursuit, goal relationship, goal interaction, goal and discourse coherence, goal realization means, goal realization condition, goal and power relationship, goal and significance, and fourth, all things in the world are structured, hierarchical, and interrelated, an overall system for a particular goal. The goal of the theory of goal is that the goal is to be such a system (Liao, 2005b, p. 352). In general, a speech activity, if not composed of only one speech act, has a general goal, with a sub-goal under the general goal, and the sub-objective may have sub-objective to form a network of destination systems. Some of the sub-objectives directly point to the general goal, and some of them are directed to the general goal. Between the sub-objective and the sub-objective, there is an organic and colorful relationship between the sub-goal and the general goal, and they interact and restrict each other.

In this system structure, the goal can be divided into primary and secondary objectives, and so on. In the interactive research of the discourse of the court, Liao Meizhen first put forward the principle of the goal of pragmatics, and explained the change of the structure of the question-and-answer behavior of the court and the question-and-answer interactive structure by the "goal principle”. The goal is different, and the way of thinking is different, the result and content of speech act are not the same. The contextual structure of contract discourse is inconsistent, and the parties to the contract are members of different social groups. Contract discourse is an interaction among different members, showing different gender, racial, and cultural factors. The different expressions and understandings of the speech goal of the members with different gender, race, and culture will lead to the unclear goal of the contract and the non-standardization of the legal language of the contract, which will eventually lead to the dispute of the contract and the trial of the case of the contract dispute by the court (Liao, 2009, p. 62). We are working hard to promote the study of the principle of goal and the subjectivity of language use. Our efforts have helped to open up new ways of pragmatics and discourse analysis.

\section{A Study of Contract Discourse}

The application of pragmatic goal theory in contract speech analysis is mainly embodied in two levels, namely, the specific contract level and contract dispute level.

\section{A Study on the Goalful Discourse at the Level of Specific Contracts Concluded by Economic Subjects}

Under the guidance of the principle of goal, we find that different economic subjects conclude different specific contracts because of different economic goals. The specific contract involves two kinds: One is the contract type, namely, the contract, the power supply contract, the water contract, the gas contract, the thermal contract, the gift contract, the loan contract, the lease contract, the financial lease contract, the contract of construction, the contract of transportation, the contract of technology, the contract of custody, the contract of warehousing, the contract of entrustment, the contract of discipline, and the contract of intermediary. The second is the types of contracts divided according to the legal characteristics, namely, paid contract and unpaid contract, Nocheng contract and practice contract, reservation contract and non-reservation contract, definite 
contract, named contract and nameless contract, dual service contract and single service contract, the main contract and the slave contract. Some contracts can only be paid, such as sale, exchange, lease, and so on; some contracts can only be free of charge, such as gift contracts; according to whether the contract is established with the delivery of the subject matter as the elements, the contract is divided into the contract and the practice contract.

\section{Normative Contracts that Meet the Requirements of Contract Law}

In order to realize the maximization of interests, protect their own legitimate rights and interests, effectively perform the contract and reduce the transaction cost, the parties to the contract strictly abide by the provisions of the contract law and the basic principles of the contract, and sign standardized contracts that meet the requirements of the contract law, such as high-tech technology contracts with high technical content. In order to achieve complete standardization, under the guidance of the principle of goal theory, we can make a goalful analysis of the discourse of technology transfer contract and patent transfer contract, whether the technology contract concluded is beneficial to the progress of science and technology, and whether it can accelerate the transformation, application, and popularization of scientific and technological achievements. In addition, the title content, progress, region, technical information, ownership and income of technical achievements, acceptance criteria, liquidated damages, project plans and task documents, feasibility demonstration and technical evaluation reports, the right to use and transfer technical achievements, etc., are analyzed. For the contract involving patent transfer, it is necessary to analyze the standardization of the name of invention and creation in the contract, the patent applicant, the validity period of patent right, and so on, so as to avoid ambiguity.

\section{Non-Standard Contracts That do not Meet the Requirements of the Contract Law}

Non-standard contracts that do not meet the requirements of the contract law generally include two cases:

Issues of both sides. Both parties to the contract do not understand the principle of goal, do not understand the legal language or even do not understand the law, resulting in contract ambiguity, contract invalidity, or contract cancellation. For this kind of non-standard contract which does not meet the requirements, it is necessary to clarify its goal, analyze the terms of the rights and obligations of the parties to the contract, find out the problem, and reduce the risk.

Unilateral issues. One party to the contract makes use of the legal language that the other party is not familiar with the law of the contract, so as to circumvent the principle of the goal of the contract or the legal language of the standard, resulting in the legal interpretation or the settlement of the contract problem in the case of the contract dispute. For this kind of contract and the parties to the contract, this paper analyzes the discourse of the contract clause by using the pragmatic principle theory, and finds out how one party to the contract sets a trap and makes use of the other party's crux, so as to protect the economic interests of the other party to the contract.

\section{A Study on Goalful Discourse at the Level of Contract Disputes}

In real life, not all specific contracts are in accordance with the norms of contract law, and not all contracts can be performed according to law. There are still a large number of disputes and contract pitfalls caused by unclear goal and irregular legal language of contracts. Taking the purchase contract as an example, this paper expounds the goalful discourse analysis of the contract dispute. Generally speaking, in the current situation of house purchase, there are two contract links, one is the deposit contract and the other is the contract of sale and 
purchase.

\section{A Study on the Goalful Discourse at the Level of Contract Disputes}

The goalful discourse analysis of the dispute level of the deposit contract is as follows: legally, the signing of the deposit contract (that is, the subscription book) is not a necessary procedure for the purchase of the house. Why do real estate developers attach great importance to deposit contracts (that is, subscriptions)? The key here is the deposit, which is the goal of the real estate developers to draw up the deposit contract. A deposit is to guarantee the formal contract of sale and purchase of houses to be signed in the future and to violate the agreement of the contract of deposit. The penalty rule of deposit shall be applied. In fact, who generally violates the agreement? The goal of real estate developers is to sell houses, sell to everyone is the same, as long as you can earn money, so default can only be the buyer, that is, the party who pays the deposit, so that developers put the deposit into the pocket after taking care of it. However, if the buyer buys a house, the deposit will be transferred to the house; if the buyer sees a more suitable house and does not want to buy it, the deposit will not be refunded (He, 2008, pp. 496-679). But, at this time, because the deposit has been paid, real estate developers do not refund the deposit, if buyers file a lawsuit, which makes themselves into a deeper level of contract disputes, so they are in a dilemma. That is to say, after the deposit contract is signed and paid, the buyer will cede the initiative of the contract negotiation to the real estate developer, putting himself in a disadvantageous position.

\section{A Study on the Goal of the Contract in the Purchase and Sale of the Contract}

The goalful discourse analysis of the dispute level of the contract of sale and purchase is as follows: The key lies in the format of the contract of sale and purchase. The usual practice is for real estate developers to provide the format text of the contract of sale and purchase, and the problem lies here, because the format text is often drawn up by the real estate developer and is from its own point of view. At the same time, the real estate developers are in the obvious monopoly position of resources and information, most of the buyers lack the knowledge of contract risk and the immaturity of consumer psychology, because of this, it is convenient for the real estate developers to make use of their advantages of housing resources, forcing the buyers to agree to sign this contract in favor of the real estate developers. In this way, the future is under the control of real estate developers. Because, as long as the buyer signs this contract, it will have to be done in accordance with the contract in the future (Qin, 2006, pp. 1-9). In the event of breach of contract, the buyer is once again in a disadvantageous position, for example, "the seller (real estate developer) shall, within 150 days after the delivery of the commodity, register the ownership and provide information to the property rights registration authority for the record. If the seller is unable to obtain the real estate ownership certificate within the prescribed time limit, the seller undertakes to continue to do so".

\section{Conclusions}

To sum up, the pragmatic principle theory, that is, the Chinese speech act theory is fully applicable to contract discourse analysis. The goal analysis of contract discourse is a whole system which echoes the macro-general goal and the micro-cosmic goal, has the structure, the hierarchy, the organic, and the interrelated whole system (Liao, 2005a, p. 5). Contract discourse is a systematic network of goal consistency, goal conflict, and goal neutrality. The difference of contract goal leads to the emergence of different contract categories. The goal of the contract is the same, which gives birth to the same "contract". The conflict of the goal of the 
contract leads to the "contract dispute" of the difference between the conclusion and the performance, and the goal of the contract is neutral, which lays the foundation and background of the cooperation among the parties. Under the guidance of the speech act theory of Liao Meizhen's goal principle, it is of great practical significance and theoretical value to study the contract discourse from four aspects: the national contract legal system, the specific contract concluded by the economic subject, the contract dispute, and the court to the trial of the contract dispute. The economic contract law of China is mainly embodied in the general principles of civil law and contract law, and a large number of contents of economic contract law are scattered in the contract norms and judicial interpretation of contracts in separate laws, such as guarantee law, copyright law, and so on. With the development of market economy in China, a large number of various types of economic contract practice have emerged.

Therefore, it is necessary to analyze the goalful discourse of economic contract in the fields of economic contract (establishment) law, economic contract conclusion, performance practice, and judicial practice of dispute settlement in economic contract cases, which is a key problem that needs to be solved urgently in the development of national economy and society. Based on the above motivation and background, it is necessary to introduce the pragmatic principle theory into the legislation of economic contract, the ambiguity of economic contract clause and the discourse analysis of contract dispute resolution. From the perspective of speech act theory between China and the West, the analysis and study of contract discourse is the direction of interdisciplinary research, which is multi-dimensional and multi-level, and has a wide range of application prospects and practical value. It is precisely because the contract is task-oriented and goal-oriented, so the speech act theory of goal principle involves the study of the subjective initiative of human speech act, and its application prospect is great. The research goal principle and the contract discourse analysis are beneficial to the further understanding of the perfection of the contract legal system, and to the improvement of the judge's contract trial level, the contract conclusion level of the main body of the contract conclusion, the defense level of the lawyer, the clarification of the rights and obligations of the parties to the contract, the practical standardization of the contract and the guarantee of the party's performance of the contract, so as to realize the economic goal of the contract and the maximization of the parties' economic interests.

\section{References}

Gao, J. S. (2004). Latest enterprise contract 300 questions. Beijing: Industry and Commerce Press.

He, Z. (2008). The principle of contract law and its practical guide (pp. 496-679). Beijing: People’s Court Press.

Kant, I. (1946). Criticism of judgment (p. 66). Beijing: Business Press.

Liao, M. Z. (2005a). Objective principle and goal analysis (I). Rhetorical Learning, (3), 5.

Liao, M. Z. (2005b). Objective principle and goal analysis (part two). Rhetorical Learning, (4), 352.

Liao, M. Z. (2009). A study on the principle of goal and the mode of communication. Journal of Foreign Language Studies, (4), 62.

Qin, B. (2006). How to sign a safe purchase contract (pp. 1-9). Beijing: Law Press.

Van-Dijk, T. A. (1980). Macrostructures: An interdisciplinary study of global structures in discourse, interaction and cognition. Hillsdale, N.J.: Lawrence Erlbaum. 